\title{
Field studies reveal a close relative of $C$. elegans thrives in the fresh figs of Ficus septica and disperses on its Ceratosolen pollinating wasps
}

\author{
Gavin C. Woodruff ${ }^{1} 2^{*}$ i] and Patrick C. Phillips ${ }^{2}$ (1)
}

\begin{abstract}
Background: Biotic interactions are ubiquitous and require information from ecology, evolutionary biology, and functional genetics in order to be understood. However, study systems that are amenable to investigations across such disparate fields are rare. Figs and fig wasps are a classic system for ecology and evolutionary biology with poor functional genetics; Caenorhabditis elegans is a classic system for functional genetics with poor ecology. In order to help bridge these disciplines, here we describe the natural history of a close relative of $C$. elegans, Caenorhabditis inopinata, that is associated with the fig Ficus septica and its pollinating Ceratosolen wasps.

Results: To understand the natural context of fig-associated Caenorhabditis, fresh F. septica figs from four Okinawan islands were sampled, dissected, and observed under microscopy. C. inopinata was found in all islands where F. septica figs were found. C.i nopinata was routinely found in the fig interior and almost never observed on the outside surface. C. inopinata was only found in pollinated figs, and C. inopinata was more likely to be observed in figs with more foundress pollinating wasps. Actively reproducing C. inopinata dominated early phase figs, whereas late phase figs with emerging wasp progeny harbored C. inopinata dauer larvae. Additionally, C. inopinata was observed dismounting from Ceratosolen pollinating wasps that were placed on agar plates. C. inopinata was not found on non-pollinating, parasitic Philotrypesis wasps. Finally, C. inopinata was only observed in F. septica figs among five Okinawan Ficus species sampled.
\end{abstract}

Conclusion: These are the first detailed field observations of C. inopinata, and they suggest a natural history where this species proliferates in early phase F. septica figs and disperses from late phase figs on Ceratosolen pollinating fig wasps. While consistent with other examples of nematode diversification in the fig microcosm, the fig and wasp host specificity of $C$. inopinata is highly divergent from the life histories of its close relatives and frames hypotheses for future investigations. This natural co-occurrence of the fig/fig wasp and C. inopinata study systems sets the stage for an integrated research program that can help to explain the evolution of interspecific interactions.

Keywords: Ficus, Fig wasp, Caenorhabditis, Natural history, Coevolution

*Correspondence: gavincw@uoregon.edu

${ }^{2}$ Department of Biology, Institute of Ecology and Evolution, University of Oregon, Eugene, OR, USA

Full list of author information is available at the end of the article

(c) The Author(s) 2018. This article is distributed under the terms of the Creative Commons Attribution 4.0 International License (http://creativecommons.org/licenses/by/4.0/), which permits unrestricted use, distribution, and reproduction in any medium, provided you give appropriate credit to the original author(s) and the source, provide a link to the Creative Commons license, and indicate if changes were made. The Creative Commons Public Domain Dedication waiver (http://creativecommons.org/ publicdomain/zero/1.0/) applies to the data made available in this article, unless otherwise stated. 


\section{Background}

Interactions at a broad range of scales structure the organization of biological systems. Within ecology, the biotic environment is a major determinant of the distribution and abundance of both species and communities, and so understanding the origins and maintenance of interspecific interactions is a key goal within the field. Yet, interspecific relationships taken as an aggregate are composed of millions of interactions between individual organisms $[1,2]$, and the nature of those individuals is in turn strongly dependent upon the interactions of thousands of genetic elements comprising their overall genetic composition [3]. Thus understanding how and why species interact with one another likely depends upon information about the genetic bases of such interactions, of which we currently know very little. A more complete analysis of all of these interactions, from gene to ecosystem, requires the development of study systems in which the power of modern genetic approaches can be used within the context of a compelling ecological circumstance. Here we seek to establish such a system using a newly discovered nematode species that lives in association with the classic fig-fig wasp ecological system [4].

Eukaryotic laboratory model systems have been rightly heralded for their contributions to our understanding of genetics [5-7]. However, only a fraction of their genes are annotated, and thousands of genes remain that have as of yet no known function [8]. Understanding the natural ecological functional context of these genes holds the potential to unlock this mysterious fraction of the genome [8]. Conversely, an understanding of the molecular biology of gene function can be used to inform ecology and evolutionary biology-those interested in the molecular basis of adaptive traits (such as the wing patterns of Heliconius butterflies [9], coat color in crows [10], visual sensitivity in fish [11, 12], the timing of maturation in platyfish $[13,14]$, and beak size in Darwin's finches [15]), physiological systems that structure species distributions (such as hemoglobin variation underlying altitudinal clines of deer mice [16] and Flowering Locus $\mathrm{C}$ and FRIGIDA variation underlying latitudinal clines of Arabidopsis [17, 18]), and the underpinnings of host-microbe interactions [1] all need functional genetic tools to address their questions [19]. Indeed, to the extent that genetic elements underlie the distribution and abundance of organisms in space (which in part defines major questions in molecular ecology), such tools will be necessary to empirically test their sufficiency [19]. Are such tools also needed to understand the interspecies interactions that underlie most ecological theory?

Successfully traversing these broad fields requires the development of appropriate study systems-particularly systems wherein questions spanning multiple levels of biological organization can be simultaneously addressed. And although there are systems with compelling ecology and evolution (such as Heliconius [20], ants/acacias [21], and Darwin's finches [22]) and systems with well-established and powerful functional genetics (such as fruit flies [6], yeast [5], and worms [7]), systems with a good knowledge of both are rare. The development of good functional genetics in established ecological systems [8] and/or the development of good ecology in established genetic systems [19] is necessary to bridge these gaps.

A classic system for coevolutionary studies is the fig microcosm [4]. The subject of decades of research efforts $[23,24]$, this system has revealed important advances regarding mate competition [25-27], sex ratio allocation $[26,28]$, and the maintenance of interspecific interactions [29], among others. Furthermore, this system entails a textbook mutualism in figs and their associated wasps: figs need wasps for pollination, and wasps lay their eggs in fig ovules [4]. A typical life cycle of a pollinating fig wasp can be defined as follows: (1) one or more winged, female wasps (known as foundresses upon fig entry) enters the fig inflorescence through a specific opening called the ostiole; (2) the foundress either actively or passively pollinates the fig florets; (3) the foundress lays eggs in the ovules (subsequent to egg-laying the foundress typically dies in the fig); (4) wasp progeny develop by feeding on fig ovule tissue; (5) pigmentless, flight-less male wasps emerge first and mate with females that have yet to emerge, and then subsequently cut a hole in the fig to enable female wasp dispersal; (6) female wasps collect pollen, exit the fig, and disperse to another fig to repeat the cycle $[4,24,30]$. Parasitic wasps are also associated with figs and their pollinating wasps $[24,31]$. These animals do not pollinate but still lay eggs in the fig, often avoiding the interior fig lumen entirely by laying eggs with a long ovipositor from the exterior fig surface. These parasitic wasps can be fig gallers (which lay eggs into fig tissue), kleptoparasites (laying eggs into existing galls made by pollinating wasps), or parasitoids (laying eggs into developing pollinating wasp larvae) [31]. Furthermore, this system is amenable to experimental manipulation in the field, and evolutionarily-relevant measurements such as the number of seeds, wasp progeny, and wasp foundresses are easily ascertained [4]. Thus, this is a powerful system for investigating a number of fundamental questions in ecological and evolution.

Various nematode species have also been associated with figs and their pollinating wasps. These have long included the plant-parasitic nematode Schistonchus (which has recently been re-systematized into the genera Schistonchus, Ficophagus, and Martininema due to paraphyly [32]) and the wasp parasitic nematode Parasitodiplogaster [33]. In the past decade, a number of 
additional nematode species have been discovered to be associated with figs. Teratodiplogaster nematodes are close relatives of Parasitodiplogaster that are nonetheless morphologically divergent and are presumptive yeast-feeders instead of wasp parasites [34-36]. Bursaphelenchus sycophilus, a close relative of fungal feeders, is a likely plant parasite of Ficus variegata [37]. The plantparasitic Ficotylus has also been associated with both fig interiors [38] as well as exterior bracts [39]. Additionally, multiple new, morphologically-divergent and highly phenotypically-plastic Pristionchus species were discovered in the figs of three different Ficus species [40]. These include likely bacteria feeders and nematode predators. This report also included sequencing data suggesting the diplogastrid Acrostichus is also associated with figs [40]. Furthermore, multiple plant parasitic nematodes have been observed to infect non-fig areas of the Ficus plant (i.e. branches, leaves, roots, etc.; Meloidogyne, Xiphinema, Heterodera, and Aphelenchoides, among others $[41,42])$. Thus multiple nematode lineages have evolved to thrive in figs through adaptation to various nutrient resource types. In addition, fig-associated nematodes are generally thought to disperse on pollinating female wasps upon their emergence (i.e., step (6) in the generic fig wasp life cycle above [43]). Consistent with this, Schistonchus [43, 44], Parasitodiplogaster [43], Teratodiplogaster [40], Pristionchus [40], and Acrostichus [40] have all been observed on emerging female pollinating wasps in the field. Schistonchus caprifici has been observed with both pollinating and parasitic wasps, although nematodes were more frequently found with pollinating wasps [44]. Furthermore, laboratory chemotaxis experiments showed that Schistonchus racemosa is more attracted to female pollinating wasps and their cuticle-derived molecules than those of parasitic wasps and male pollinating wasps [45]. This is all consistent with wasp-mediated dispersal being an essential component of the fig nematode life cycle.

As figs and fig wasps have long been used for evolutionary studies, a classic model system for functional genetics is the nematode Caenorhabditis elegans. Like most genetic models, it is easy to rear in the laboratory and is amenable to sophisticated genetic manipulations. Furthermore, the background knowledge concerning its molecular, cellular, and developmental biology is simply vast-we arguably know more about this species than any other metazoan [7]. Recently, the nematode Caenorhabditis inopinata (formerly known as Caenorhabditis sp. 34), a novel sister species to C. elegans, was discovered in Okinawa, Japan $[46,47]$. In contrast to $C$. elegans, $C$. inopinata is not a self-fertile hermaphrodite but rather an obligate male/female species [46, 47], like most members of the genus [48]. Furthermore, unlike its close relatives, which thrive in rotting plant material [49], C. inopinata was found inside the fresh figs of Ficus septica [47]. In addition to its novel ecological context, $C$. inopinata is morphologically divergent from $C$. elegans in multiple respects, despite its phylogenetic position. $C$. inopinata is very long in size, growing to be on average nearly twice as long as C. elegans, and this size difference can be largely attributed to postembryonic changes in cell size [47]. In addition, $C$. inopinata develops about twice as slowly as C. elegans, has much shorter tail spikes than C. elegans, and harbors enormous sperm that are three times larger in diameter than those of $C$. elegans, among other morphological differences [47]. Furthermore, unlike most fig-associated nematodes, $C$. inopinata is culturable in the laboratory on bacteria-seeded agar plates $[46,47]$. As multiple reverse genetic techniques are applicable across the genus [50,51] as well as in this species [46], C. inopinata is particularly well-positioned to connect functional genetics with natural ecology. To this end, here for the first time we describe the natural context of $C$. inopinata through the observation of dissected fresh figs. We examine the extent of $C$. inopinata host specificity with both fig and wasp species, the co-occurrence of worm and fig developmental stages, and the ability of worms to disperse on wasps, with a focus on the implications of these observations for continued studies in both the C. inopinata and fig/fig-wasp systems.

\section{Methods \\ Collection sites}

C. inopinata was originally isolated from the fresh (that is, not rotting and still attached to the tree) figs of Ficus septica on the island of Ishigaki in Okinawa Prefecture, Japan by Natsumi Kanzaki (Fig. 1) [46]. To further probe the natural context of this species, F. septica figs were sampled from additional Okinawan islands of Iriomote, Miyako, and Yonaguni (Fig. 2, Tables 1, 2, 3, and Additional File 1). F. septica was typically found at the edge of vegetation on roadsides, but sampling was also performed in the public areas of Banna Park (Ishigaki) and Uenootakejoshi Park (Miyako). In May 2015 and May 2016, additional Ficus species were also sampled when accessible figs were found. Images revealing geographic position information of sampled plants were generated with Mapbox [52].

\section{DNA sequencing}

Ficus, wasp, and nematode species from natural collections (see below) were initially identified via morphological characteristics. Subsequently, DNA was isolated from some ethanol-preserved, $F$. septica-derived wasp and nematode specimens and sequenced to verify genus identity. For wasp samples, preserved animals were 


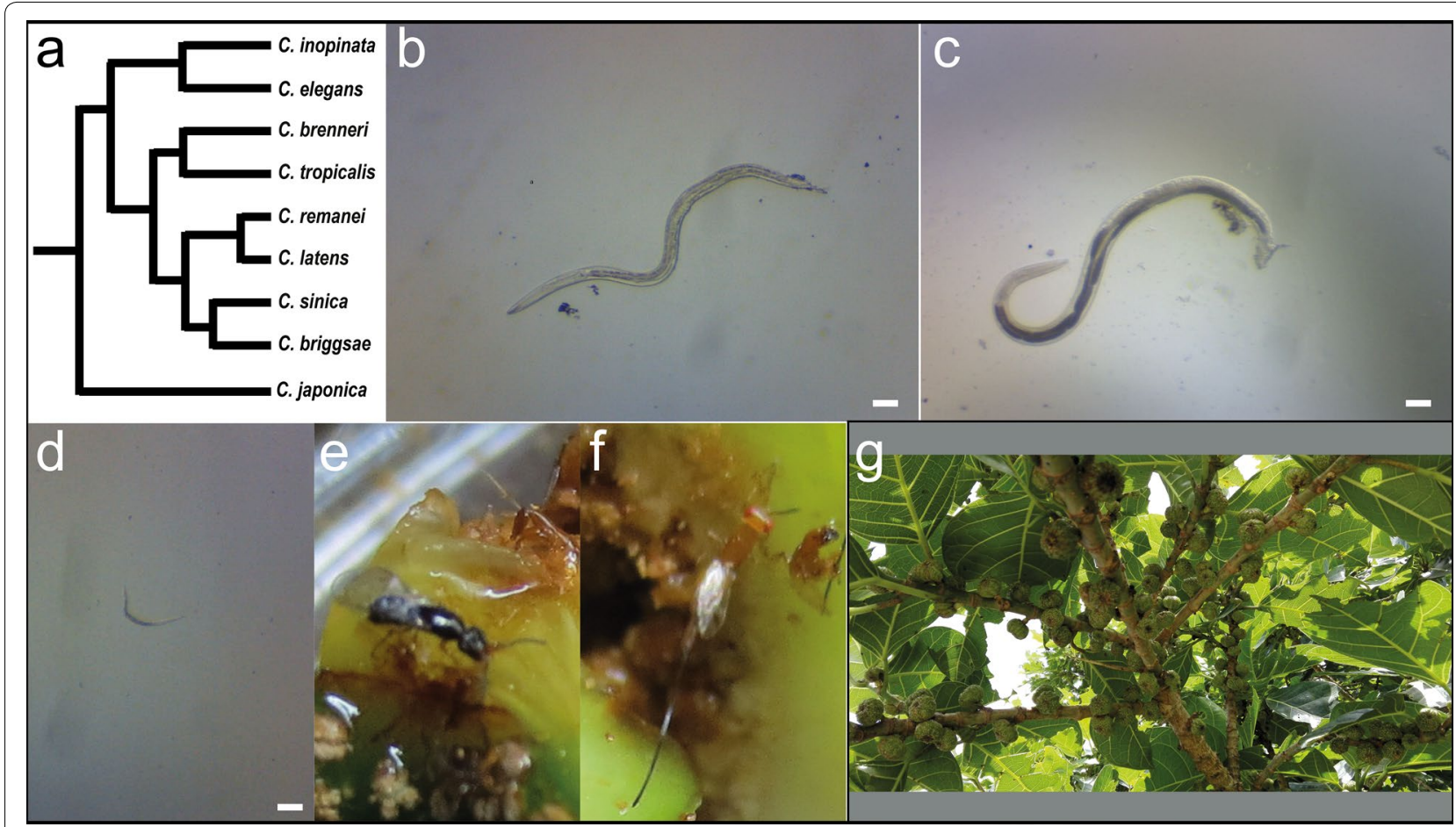

Fig. 1 Caenorhabditis inopinata is associated with fresh Ficus septica figs and fig wasps. a A cladogram revealing the evolutionarily relationships of Caenorhabditis, following $[46,47]$. The fig-associated C. inopinata is among the closest known relatives of the important model organism, C. elegans. This reduced figure excludes many known species in this group [53]. b An adult C. inopinata female isolated from a fresh F. septica fig. c An adult C. inopinata male isolated from a fresh F. septica fig. d A C. inopinata dauer larva isolated from a fresh F. septica fig. All scale bars in (b-d) are 100 microns. e A female Ceratosolen pollinating wasp. f A Philotrypesis parasitic wasp. g A F. septica plant

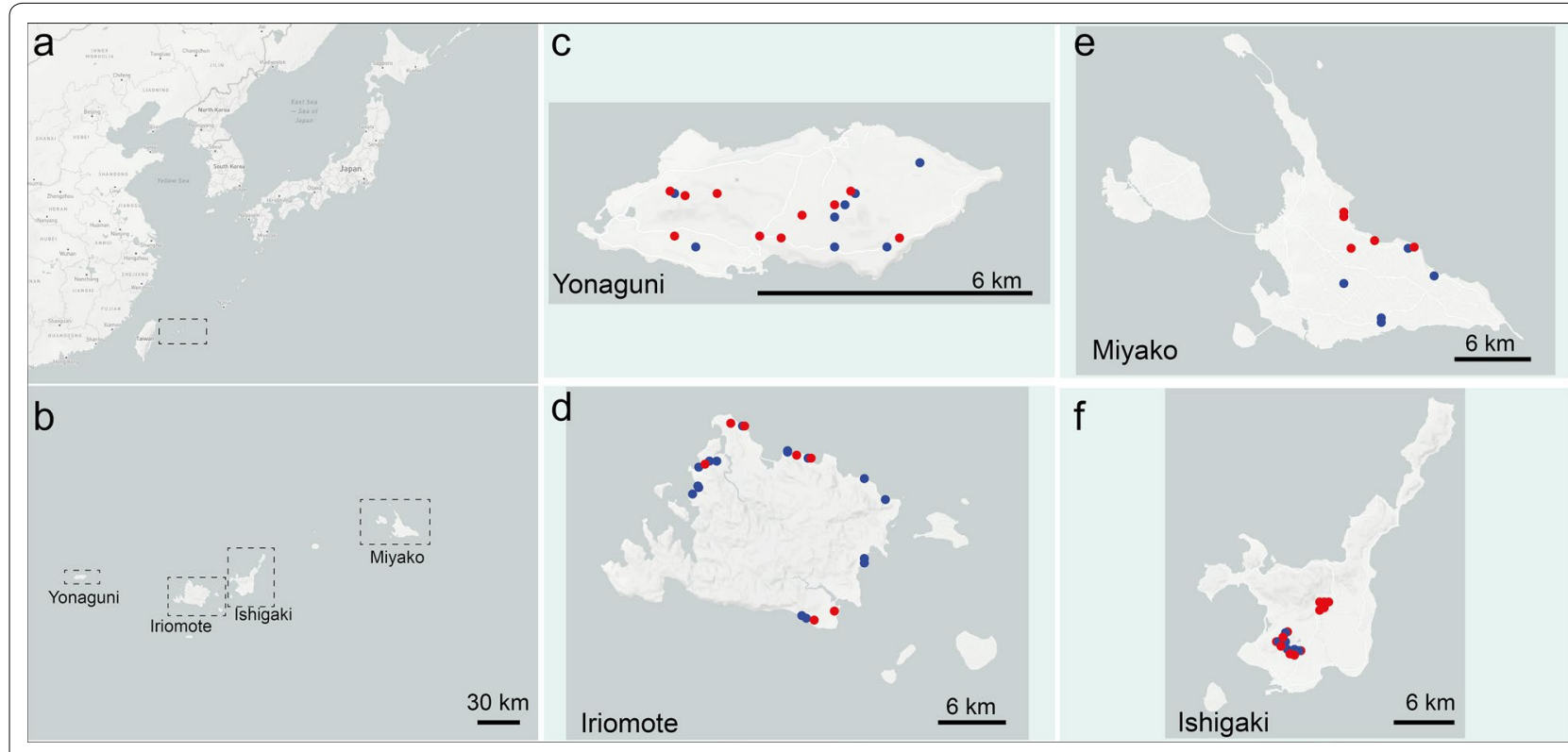

Fig. 2 Ficus septica fig collection sites in 2016. a, b Figs were collected in four of the Sakishima Islands (a, boxed region) of Okinawa Prefecture, Japan: Yonaguni (c), Iriomote (d), Miyako (e), and Ishigaki (f). Blue circles represent positions of F. septica plants where Caenorhabditis inopinata nematodes were found, and red circles denote positions of F. septica plants where C. inopinata nematodes were not found in dissected figs 
Table 1 Caenorhabditis inopinata occupancy in Ficus septica figs in 2016: all sampled plants

\begin{tabular}{|c|c|c|c|c|c|c|}
\hline Island & All plants ${ }^{a}$ & $\begin{array}{l}\text { Plants with } C . \\
\text { inopinata }^{\mathbf{b}}\end{array}$ & $\begin{array}{l}\text { Plants without } C \text {. } \\
\text { inopinata }^{c}\end{array}$ & All Figs ${ }^{d}$ & Figs with C. inopinata ${ }^{\mathrm{e}}$ & $\begin{array}{l}\text { Figs } \\
\text { without } C \text {. } \\
\text { inopinata }\end{array}$ \\
\hline Iriomote & 27 & $19(0.70)$ & $8(0.30)$ & 86 & $49(0.57)$ & $37(0.43)$ \\
\hline Ishigaki & 24 & $6(0.25)$ & $18(0.75)$ & 36 & $7(0.19)$ & $29(0.81)$ \\
\hline Miyako & 10 & $6(0.60)$ & $4(0.40)$ & 79 & $17(0.22)$ & $62(0.78)$ \\
\hline Yonaguni & 23 & $10(0.43)$ & $13(0.57)$ & 49 & $22(0.45)$ & $27(0.55)$ \\
\hline Total & 84 & $41(0.49)$ & $43(0.51)$ & 250 & $95(0.38)$ & $155(0.62)$ \\
\hline
\end{tabular}

a The number of $F$. septica plants from which figs were picked and dissected. This includes all such plants, regardless of nematode occupancy or pollination status

b The number of F. septica plants from which at least one dissected fig harbored C. inopinata. Fraction of all plants (denominator in Column 2) in parentheses

c The number of $F$. septica plants from which no dissected figs harbored C. inopinata. Fraction of all plants (denominator in Column 2 ) in parentheses

$d$ The number of dissected $F$. septica figs, regardless of nematode occupancy or pollination status

e The number of dissected F. septica figs harboring C. inopinata, regardless of pollination status. Fraction of all figs (denominator in Column 5 ) in parentheses

${ }^{f}$ The number of dissected F. septica figs that did not contain C. inopinata, regardless of pollination status. Fraction of all figs (denominator in Column 5 ) in parentheses

Table 2 Caenorhabditis inopinata occupancy and pollination status among Ficus septica figs in 2016: plants without C. inopinata

\begin{tabular}{|c|c|c|c|c|c|c|}
\hline Island & Plants $^{a}$ & Figs $^{b}$ & Pollinated figs ${ }^{c}$ & Unpollinated figs $^{d}$ & $\begin{array}{l}\text { Figs with } C \text {. } \\
\text { inopinata }^{\mathrm{e}}\end{array}$ & $\begin{array}{l}\text { Figs } \\
\text { without } C \text {. } \\
\text { inopinata }\end{array}$ \\
\hline Iriomote & 8 & 8 & $7(0.87)$ & $1(0.13)$ & 0 & 8 \\
\hline Ishigaki & 18 & 20 & $19(0.95)$ & $1(0.05)$ & 0 & 20 \\
\hline Miyako & 4 & 22 & $4(0.18)$ & $18(0.82)$ & 0 & 22 \\
\hline Yonaguni & 13 & 16 & $16(1)$ & $0(0)$ & 0 & 16 \\
\hline Total & 43 & 66 & $46(0.70)$ & $20(0.30)$ & 0 & 66 \\
\hline
\end{tabular}

a The number of F. septica plants from which figs were picked and dissected yet none harbored C. inopinata. This includes all such plants, regardless of fig pollination status

b The number of dissected F. septica figs from plants that did not harbor C. inopinata, regardless of pollination status

c The number of dissected, pollinated $F$. septica figs from plants that did not harbor Caenorhabditis inopinata. Fraction of all figs from plants that did not harbor $C$. inopinata (denominator in Column 3 ) in parentheses

d The number of dissected, unpollinated F. septica figs from plants that did not harbor Caenorhabditis inopinata. Fraction of all figs from plants that did not harbor $C$. inopinata (denominator in Column 3 ) in parentheses

e The number of dissected F. septica figs harboring C. inopinata from plants that did not harbor C. inopinata

$\mathrm{f}$ The number of dissected F. septica figs not harboring C. inopinata from plants that did not harbor Caenorhabditis inopinata

washed three times in PBS and subsequently crushed with a pestle in a $1.5 \mathrm{~mL}$ Eppendorf tube. DNA was then isolated from the suspension with a Qiagen Blood and Tissue DNeasy kit. For worm DNA samples, preserved single individuals were washed three times in PBS and digested with $5 \%$ Proteinase $\mathrm{K}$ in Tris-EDTA buffer for $1 \mathrm{~h}$ at $58{ }^{\circ} \mathrm{C}$. This solution was immediately used for PCR after a $10 \mathrm{~min}, 95^{\circ} \mathrm{C}$ incubation for enzyme deactivation. For wasp and nematode identification, the mitochondrial cytochrome oxidase I (COI) locus was amplified with primers LCO1490 (5'-GGTCAACAAATCATA AAGATATTGG-3') and HCO2198 (5'-TAAACTTCA GGGTGACCAAAAAATCA-3') [54]. PCR reactions were performed with the New England BioLabs Phusion High Fidelity PCR kit. For all reactions this thermocycler program was implemented: $98{ }^{\circ} \mathrm{C}$ for $10 \mathrm{~min}$. initial denaturation; $98{ }^{\circ} \mathrm{C}$ for $10 \mathrm{~s}$. denaturation; $45^{\circ} \mathrm{C}$ for $30 \mathrm{~s}$. annealing; $72{ }^{\circ} \mathrm{C}$ for $30 \mathrm{~s}$. extension $\left(37\right.$ cycles); $72{ }^{\circ} \mathrm{C}$ for $10 \mathrm{~min}$. final extension. Sanger sequencing was performed by Genewiz. Sequences were then queried with BLAST to the NCBI GenBank database to identify closely related taxa (see Additional files 2,3). COI sequences of known fig-associated nematodes Parasitodiplogaster salicifoliae (GenBank accession KP015022) and Schistonchus guangzhouensis (now known as Martininema guangzhouensis [32]; GenBank accession EU419757), and the marine rhabditid Litoditis marina (which was a high BLAST hit for an unidentified nematode species found among our preserved specimens, GenBank accession KR815450) were retrieved from GenBank. Sequences 
Table 3 Caenorhabditis inopinata occupancy and pollination status among Ficus septica figs in 2016: plants with C. inopinata

\begin{tabular}{|c|c|c|c|c|c|c|c|c|}
\hline Island & Plants $^{a}$ & Figs $^{b}$ & Pollinated figs ${ }^{c}$ & Unpollinated figs ${ }^{d}$ & $\begin{array}{l}\text { Figs with } C . \\
\text { inopinata }^{\mathrm{e}}\end{array}$ & $\begin{array}{l}\text { Figs } \\
\text { without } C \text {. } \\
\text { inopinata }^{f}\end{array}$ & $\begin{array}{l}\text { Pollinated } \\
\text { figs with } C \text {. } \\
\text { inopinata }^{g}\end{array}$ & $\begin{array}{l}\text { Unpollinated } \\
\text { figs with C. } \\
\text { inopinata }^{\mathrm{h}}\end{array}$ \\
\hline Iriomote & 19 & 78 & $78(1)$ & $0(0)$ & $49(0.63)$ & $29(0.37)$ & $49(0.63)$ & 0 \\
\hline Ishigaki & 6 & 16 & $16(1)$ & $0(0)$ & $7(0.44)$ & $9(0.56)$ & $7(0.44)$ & 0 \\
\hline Miyako & 6 & 57 & $55(0.96)$ & $2(0.04)$ & $17(0.30)$ & $40(0.70)$ & $17(0.31)$ & 0 \\
\hline Yonaguni & 10 & 33 & $33(1)$ & $0(0)$ & $22(0.67)$ & $11(0.33)$ & $22(0.67)$ & 0 \\
\hline Total & 41 & 184 & $182(0.99)$ & $2(0.01)$ & $95(0.52)$ & $89(0.48)$ & $95(0.52)$ & 0 \\
\hline
\end{tabular}

a The number of $F$. septica plants from which at least one fig was picked, dissected, and did harbor $C$. inopinata. This includes all such plants, regardless of fig pollination status

b The number of dissected F. septica figs from plants that did harbor C. inopinata, regardless of pollination status

c The number of dissected, pollinated F. septica figs from plants that did harbor C. inopinata. Fraction of all figs from plants that harbored C. inopinata (denominator in Column 3) in parentheses

d The number of dissected, unpollinated F. septica figs from plants that did harbor C. inopinata. Fraction of all figs from plants that harbored C. inopinata (denominator in Column 3) in parentheses

e The number of dissected F. septica figs harboring C. inopinata from plants that did harbor C. inopinata, regardless of pollination status. Fraction of all figs from plants that harbored C. inopinata (denominator in Column 3) in parentheses

f The number of dissected F. septica figs not harboring C. inopinata from plants that did harbor $C$. inopinata, regardless of pollination status. Fraction of all figs from plants that harbored C. inopinata (denominator in Column 3) in parentheses

$g$ The number of dissected, pollinated F. septica figs harboring C. inopinata from plants that harbored C. inopinata. Fraction of pollinated figs from plants that harbored C. inopinata (denominator in Column 4) in parentheses

$\mathrm{h}$ The number of dissected, unpollinated $F$. septica figs not harboring C. inopinata from plants that did harbor C. inopinata

of Pristionchus pacificus, Caenorhabditis japonica, and C. elegans were retrieved from WormBase [55]. The C. inopinata COI sequence was retrieved from the genome assembly (https://www.ncbi.nlm.nih.gov/nucco re?term $=382947 \% 5$ BBioProject\%5D) [46]. Sequences were aligned with MUSCLE [56].

\section{Fig dissections and developmental stage classification}

Figs were kept refrigerated and dissected $<9$ days after sampling. Figs were cut into four pieces in tap water in $60 \mathrm{~mm}$ petri dishes. In 2015, figs were only scored for $C$. inopinata presence and fig pollination status. Whereas in May 2016, figs were additionally scored for fig developmental stage, wasp foundress number, and surface nematodes. Unless otherwise noted, the data reported in this study are derived from the larger 2016 set. A fraction of $F$. septica figs (131/250 dissected figs) were initially washed with tap water before dissection in order to interrogate the presence of fig surface nematodes. Dissected figs were then assayed for fig developmental stage, foundress number (in only 169/250 of dissected F. septica figs), and the presence of $C$. inopinata under a dissection microscope. Caenorhabditis nematodes exhibit a stereotypical pharyngeal morphology that was used for species identification [57]. Figs were binned into five stages based on fig wasp development (inspired by the system developed in [23]; Fig. 4a-e): not pollinated (Phase A), pollinated with no apparent developing wasps (Phase B), developing wasp progeny apparent (Phase $\mathrm{C}$ ), wasp progeny emerging (Phase D), and post-wasp emergence (Phase E). In figs where foundress wasps were unambiguous, they were counted. C. inopinata animals were binned into reproductive phase (third larval stage, fourth larval stage, and adult; Fig. 1b, c) or dispersal phase (Fig. 1d). First and second larval stage animals were observed but not noted as they tended to coincide with adult animals and were more difficult to morphologically distinguish with a dissecting microscope (Caenorhabditis nematodes are generally thought to have overlapping generations [58]). The dispersing morphotype (Fig. 1d) that dominated later stage figs (Fig. 4f) was confirmed to be C. inopinata in the field via pharynx morphology under higher magnification compound light microscopy, DNA sequencing (Additional files 2, 3), and their development into fourth larval and adult $C$. inopinata stages under culture conditions (Fig. 5). As stress conditions can promote both first larval stage arrest and dauer larva formation in Caenorhabditis nematodes [59], and the microscopic power necessary to identify key morphological features of dauer larvae [60] was not available in the field, it remains possible that it is early (first or second) larval stages that are dispersing and not the dauer larvae. However, because dauer larvae are the dominant dispersing stage in Caenorhabditis and other nematodes [61-63], we assume in this work that this stage is the dauer larva. Regardless, reproductive (non-dauer developmental stages) or dauer C. inopinata were noted as "abundant" if $\geq 20$ individuals were observed and "rare" if $<20$ individuals were 
observed. Dissected figs were observed under a Nikon SMZ-2 dissection microscope, and pharynx morphologies in young dauer larvae were observed with mounted live specimens under an AmScope M100C-LED compound light microscope.

\section{Wasp capture, nematode dispersal observations, and fig temperature measurements}

Parasitic and pollinating fig wasps emerging from intact F. septica figs were caught in a plastic bag (Fig. 1e). These insects were then killed and placed on Nematode Growth Medium (NGM) agar plates seeded with E. coli OP50 bacteria [64]. Plates were monitored for disembarking nematodes $3 \mathrm{~h}$ and 2 days after plating. Nematodes of a given morphotype were confirmed to be $C$. inopinata via pharyngeal morphology and, in some cases, subsequent development into reproductive phase $C$. inopinata (Fig. 5).

Additionally, interior and exterior F. septica figs temperatures were measured with a DeltaTrack needle thermometer. Each interior measurement was performed on one fresh fig on the tree, and 4-5 figs were measured per plant. These data were taken from about 11:30 AM to 1:30 p.m. on May 15, 2016 on Yonaguni Island.

\section{Results}

\section{C. inopinata is found inside the fresh, pollinated figs of Ficus septica}

C. inopinata was originally isolated from a fresh (not rotten) fig of Ficus septica in Okinawa, Japan [46]. To further explore the natural context of this species, F. septica figs were collected from additional Okinawan islands (Tables 1, 2, 3, Fig. 2, Additional file 1, dissected, and observed under a dissection microscope for the presence of C. inopinata. C. inopinata nematodes were found on all four islands where F. septica was sampled (Tables 1, 2, 3, Fig. 2). In May 2015, F. septica was sampled from Ishigaki and Iriomote islands (Additional file 4: Table S4), whereas in May 2016 sampling of figs was expanded to include the islands of Ishigaki, Iriomote, Miyako, and Yonaguni (Tables 1, 2, 3, Fig. 2). Sampling was also attempted on the islands of Okinawa (main island) and Tarama: F. septica was not found at all on Tarama, and although $F$. septica was identified on Okinawa main island, figs were not sampled because no easily-accessible figs could be picked. Although the fraction of F. septica plants harboring C. inopinata in 2016 was largely consistent across islands (G-test of independence $p=0.183$, Tables 1, 2, 3, Additional file 4: Tables S1-S3), the fraction of figs with $C$. inopinata showed island-specific differences (G-test of independence $\mathrm{p}<0.001$, Tables 1,2 , 3, Additional file 4: Table S2). Specifically, the C. inopinata fig occupancy was greater in the two western-most islands of Yonaguni and Iriomote than in the eastern islands of Ishigaki and Miyako (Tables 1, 2, 3). These island-specific differences hold even after excluding unpollinated figs (G-test of independence $\mathrm{p}<0.001$, Additional file 4: Table S3), which were overrepresented on Miyako (Tables 2,3) and were not expected to harbor nematodes (see below). Additionally, few differences were detected between field work seasons (Tables 1, 2, 3, Additional file 4: Tables S4, S5). However, C. inopinata was found less frequently in plants in Ishigaki in 2016 (25\% of plants compared to $79 \%$ in 2015, Fisher's exact test $\mathrm{p}=0.0022$ ). Also, between-island differences in fig and plant Caenorhabditis occupancy could not be detected in 2015 (Fisher's exact test $\mathrm{p}=0.29$ and 1 , respectively, Additional file 4: Table S4).

C. inopinata was originally recovered from a dissected fig. To confirm that $C$. inopinata proliferates in the interior of the fig and not on its surface, F. septica figs were initially washed in tap water and observed under microscopy before and after dissection. The frequency of $C$. inopinata observed in washed fresh figs is nearly nonexistent (1 out of 131) compared to that of those subsequently dissected (51 out of 131; Fisher's exact test $\mathrm{p}<0.001$ ). Thus, C. inopinata is associated with the fig interior and not its surface.

Plants of the genus Ficus are renowned for their classic mutualism with pollinating fig wasps [4], and there are a number of Ficus-associated nematodes that require such wasps to complete their life cycle [43]. To interrogate whether this might also hold for fig-associated Caenorhabditis, F. septica figs were also queried for their pollination status, which can be ascertained by the presence of developing seed or pollinating wasp progeny. In both field work seasons, $C$. inopinata animals were never observed in unpollinated $F$. septica figs (Tables 2, 3 ; in 2015, 0/28 unpollinated figs harbored C. inopinata). Thus, $C$. inopinata likely requires pollinating fig wasps in order to thrive.

In addition to pollination status, the number of foundress pollinating wasps per F. septica fig was noted. Typically, female pollinating wasps enter the fig, pollinate it, lay eggs in the fig ovules, and die [4]. In a number of cases, a given fig can have multiple foundresses, which can have profound impacts on wasp population dynamics $[27,28,65]$. Indeed, it was observed that the frequency of $C$. inopinata increases with foundress wasp number (Fig. 3, Additional file 4: Table S6). The mean foundress number per fig was more than twice as high in figs with $C$. inopinata ( 2.8 wasps, $\mathrm{SDM}= \pm 1.3, \mathrm{~N}=72$ ) than in those without (1.1 wasps, $\mathrm{SDM}= \pm 0.83, \mathrm{~N}=97$; Mann-Whitney $U \mathrm{p}<0.001$; see Additional file 4: Figure S1 for the distribution of observed foundresses across pollinated and unpollinated F. septica figs). Thus, higher 


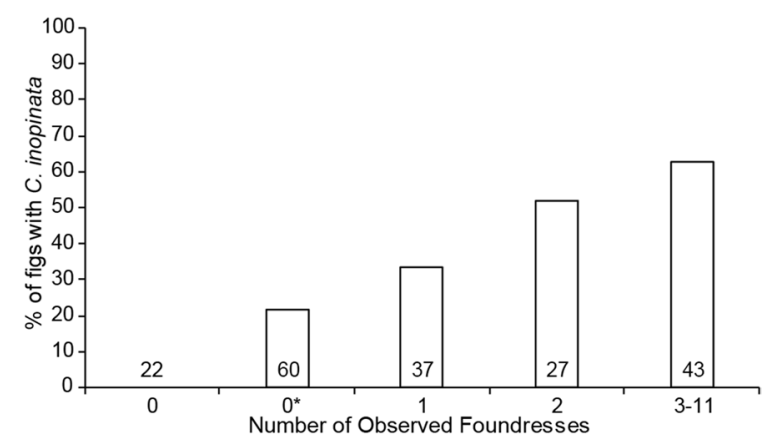

Fig. 3 Caenorhabditis inopinata is more likely to be found in figs with multiple foundresses. Graphed are the percentages of dissected F. septica figs harboring C. inopinata by Ceratosolen pollinating foundress wasp number. " ${ }^{*}$ " includes figs that were pollinated but no foundress wasps were seen, whereas "0" notes figs that were not pollinated. Numbers above the $x$-axis represent fig sample sizes

foundress number is associated with $C$. inopinata fig occupancy, suggestive that these nematodes disperse on pollinating fig wasps.

\section{C. inopinata reproduces in early phase figs and disperses in late phase figs}

Caenorhabditis nematodes can undergo alternative developmental trajectories depending on environmental conditions [66, 67]. If conditions are favorable, animals develop into adults capable of reproduction. But in crowding, starvation, or otherwise stressful conditions, animals develop into the long-lived, stress-resistant dauer larva [66]. It is this dauer stage that is used for dispersal to new food sources in the wild [67]. Previous investigations of fig-associated nematodes have measured the frequency of given nematode developmental stages across fig developmental stages to infer natural histories $[40,43]$. To this end, dissected F. septica figs were binned into five developmental stages based on wasp presence and development (Fig. 4a-e; inspired by the system developed in [23]): not pollinated (Phase A, Fig. 4a); pollinated with no apparent developing wasps (Phase B, Fig. 4b); developing wasp progeny apparent (Phase $\mathrm{C}$, Fig. 4c); wasp progeny emerging (Phase D, Fig. 4d); and post-wasp emergence (Phase E. Figure 4e). Then, figs were assayed for the presence of rare $(<20$ individuals $)$ or abundant $(\geq 20$ individuals) $C$. inopinata reproductive stage (nondauer larva developmental stages; Fig. 1b, c) or dauer larval stage (Fig. 1d) animals. Figure 4 f summarizes the results, and it is clear that reproducing $C$. inopinata dominate early phase figs. Additionally, C. inopinata dauers are not found in early phase figs and rather are only found in late phase figs that are associated with emerging wasp progeny. Furthermore, subsequent
DNA sequencing using fixed Ficus-derived specimens revealed that these dispersal larvae share near identical sequence similarity to sequence retrieved from the C. inopinata genome assembly (Additional files 2, 3), suggestive of identical species status. This distribution of nematode developmental stages then suggests a life cycle wherein nematode founders are dispersed by pollinating wasps, proliferate within the early phase figs, and then generate dispersal forms upon the emergence of wasp progeny.

\section{C. inopinata is observed on Ceratosolen pollinating wasps but not Philotrypesis parasitic wasps}

To confirm the dispersal of $C$. inopinata by fig wasps, emerging Ceratosolen pollinating wasps and Philotrypesis parasitic wasps were caught in a plastic bag, killed, and placed onto agar plates. Plates were then subsequently monitored at $3 \mathrm{~h}$ and 2 days later for the presence of $C$. inopinata nematodes. C. inopinata was observed traveling on pollinating wasps (11/29 wasps; Fig. 5) but was never observed on parasitic wasps (0/30 wasps; Fig. 5). Of the 11 wasps harboring $C$. inopinata, there was a median of 2 worms per wasp (range 1-6; Fig. 6). This was despite both species of wasps emerging from the same figs and the same plant. Thus, C. inopinata disperses on Ceratosolen pollinating fig wasps, and furthermore, $C$. inopinata may host-seek within the fig in order to find a preferred carrier.

\section{Caenorhabditis has only been found in F. septica figs among Okinawan Ficus}

A number of Caenorhabditis species are associated with a variety of plant substrates $[68,69]$. However, pollinating fig wasps tend to be associated with only one or two species of Ficus [4, 70], which suggests that fig waspassociated Caenorhabditis may also be limited to specific Ficus species. To determine if this is so, figs from additional Okinawan Ficus species were sampled. Of the nine Ficus species reported to be in the sampling locales [71], four species were found with fresh figs aside from F. septica (Table 4). No figs aside from F. septica were found to contain C. inopinata nematodes (Table 4), despite some of these species being known to harbor multiple nematode groups $[35,72]$. Thus, this particular fig-associated C. inopinata is possibly a host specialist and restricted to one species of Ficus, however more extensive sampling is required to confirm this association.

\section{F. septica figs harbor interior temperatures that are comparable to $C$. inopinata lab-rearing temperatures} The environmental parameters defining Caenorhabditis ecological niche space are nearly entirely unknown [68]. Among these, temperature influences a multitude 

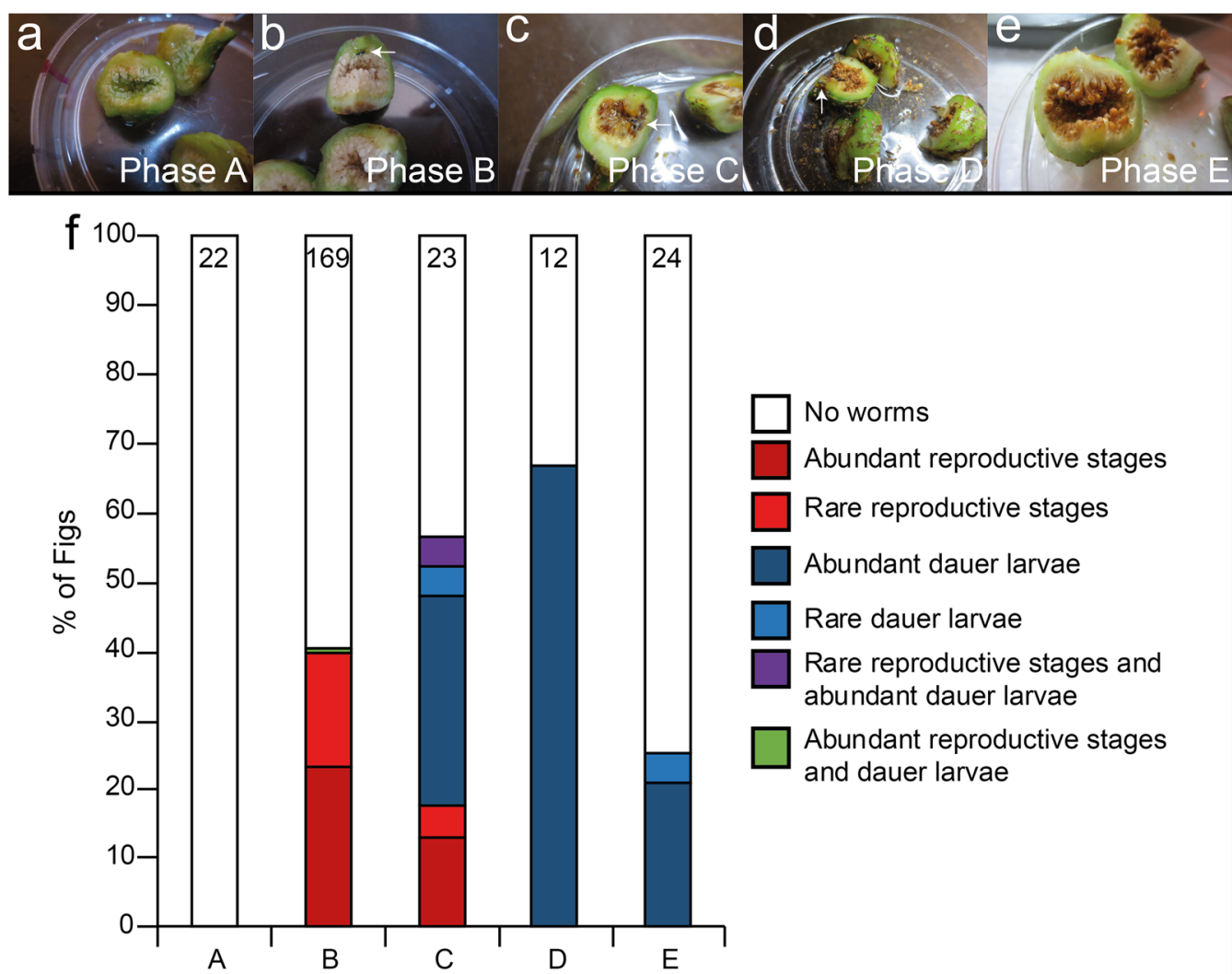

No worms
Abundant reproductive stages

Rare reproductive stages

Abundant dauer larvae

Rare dauer larvae

Rare reproductive stages and abundant dauer larvae

Abundant reproductive stages and dauer larvae

Fig Phase

Fig. 4 Caenorhabditis inopinata proliferates in early phase figs and disperses in late phase figs. a-e Dissected figs were binned into five developmental stages based on wasp presence and developmental progression: a not pollinated (Phase A), b pollinated with no apparent developing wasps (Phase B, arrow noting foundress pollinating wasp), c developing wasp progeny apparent (Phase C), $\mathbf{d}$ wasp progeny emerging (Phase D, arrow noting emerging wasp progeny), and e post-wasp emergence (Phase E). The presence of abundant ( $\geq 20$ individuals) or rare ( $<20$ individuals) reproductive stage (not dauer larvae) or C. inopinata dauer larvae were noted in each dissected fig (see methods). $\mathbf{f}$ Frequency of observed C. inopinata developmental stage by fig developmental stage. Reproductive C. inopinata (i.e., developmental stages that are not dauer larvae) predominates in Phase B and Phase C figs, whereas C. inopinata dauer larvae dominate in Phase D and Phase E figs. C. inopinata was not observed in figs that were not pollinated. The number of figs dissected per stage is noted at the top of each bar. Reproductive stage and dauer $C$. inopinata frequencies were different between fig stages (G-test of independence $p$-values $<0.001$ for both adult and dispersal types). Nematodes from the fig interior were used for all of these observations. Fisher's exact test $p$-values for all pairwise comparisons can be found in Additional file 4: Tables S7, S8

of life history traits in Caenorhabditis, including survival and reproductive rate $[73,74]$, as well as the dauer entry switch [75]. To further understand the context of wild C. inopinata, interior $F$. septica live figs and exterior ambient temperatures were measured (Fig. 7). Interior fig temperatures $\left(\right.$ mean $=28.7{ }^{\circ} \mathrm{C}, \mathrm{SDM}= \pm 1.2$, $\mathrm{n}=39$ ) were on average $2.4^{\circ} \mathrm{C}$ cooler than exterior temperatures $\left(\right.$ mean $=31.1{ }^{\circ} \mathrm{C}, \mathrm{SDM}= \pm 1.5, \mathrm{n}=39$, t-test $\mathrm{p}$-value $<0.001)$. Interior fig temperatures were comparable to laboratory rearing conditions of $C$. inopinata, wherein the temperature of $25{ }^{\circ} \mathrm{C}$ [47] was utilized. Regardless, these observations provide a unique snapshot into the natural context of $C$. inopinata. Future estimates of additional natural environmental parameters will be essential in informing hypotheses regarding the evolution and ecology of these organisms (i.e., what environmental factors are most relevant for fitness, divergence, and speciation in nematodes? [68]).

\section{Discussion}

The intricacy of the fig microcosm has facilitated decades of evolutionary and ecological field studies [4, 30]. It harbors a plethora of diverse interspecific interactions: the fig-pollinating wasp mutualism; fig-ant mutualism [76]; fig-nonpollinating wasp parasitism [31]; nematode-wasp parasitism [43]; fig nematode-fig parasitism [37, 32]; and moth-fig parasitism [77]. Figs are also a key resource for over a thousand bird and mammal species, who in turn aid in seed dispersal [78]. As a consequence of this microcosm complexity, this remains an influential and 
Table 4 Caenorhabditis has not been observed in Ficus species other than Ficus septica

\begin{tabular}{lllll}
\hline Ficus species & $\begin{array}{l}\text { Figs } \\
\text { dissected }^{\text {a }}\end{array}$ & $\begin{array}{l}\text { Figs with C. } \\
\text { inopinata }^{\mathbf{b}}\end{array}$ & $\begin{array}{l}\text { Pollinated } \\
\text { figs }^{\mathbf{c}}\end{array}$ & $\begin{array}{l}\text { Plants } \\
\text { sampled }^{\mathbf{d}}\end{array}$ \\
\hline 2015 & & & & \\
F. superba & 10 & 0 & - & 1 \\
F. microcarpa & 15 & 0 & 15 & 1 \\
F. erecta & 15 & 0 & 3 & 1 \\
2016 & & & & \\
F. variegata & 10 & 0 & 7 & 2 \\
F. microcarpa & 25 & 0 & 25 & 2 \\
F. erecta & 36 & 0 & 36 & 2 \\
\hline Fenorhabdits & & 0 &
\end{tabular}

Caenorhabditis inopinata has not yet been observed in Ficus species other than Ficus septica. Non-F. septica figs were dissected in May 2015 and May 2016. There have been eight species of Ficus aside from F. septica reported on these islands [52]. Caenorhabditis inopinata was not observed in five of these (F. caulocarpa, $F$. ampelas, F. benguetensis, and $F$. virgata figs were not found). "-" = not recorded

a The number of dissected figs, regardless of nematode occupancy or pollination status

b The number of dissected figs harboring Caenorhabditis inopinata, regardless of pollination status

c The number of dissected figs that were also pollinated

d The number of Ficus plants from which figs were picked and dissected. This includes all such plants, regardless of nematode occupancy or pollination status

active system for study in ecology and evolution [79-82]. However, none of the species in these communities are particularly amenable to functional genetics and laboratory studies-both of which are crucial for refining the explanatory power of evolutionary science. Conversely, as thousands of genes in multiple long-standing eukaryotic laboratory model systems have no known functions [8], it is likely that their natural ecological contexts (which have often been neglected) will be needed to thoroughly understand their genomes. As a consequence, there have been calls to integrate ecological, evolutionary, and functional genetic approaches [8, 19]. Here, we have described the natural history of $C$. inopinata, a close relative of the model genetic organism $C$. elegans. What has been observed in this Caenorhabditis study, together with the known biology of the fig microcosm, can then be used to inform hypotheses regarding the evolution of interspecific relationships in both systems.

Caenorhabditis species typically proliferate on rotting plants and disperse on invertebrate carriers. And although the features defining niche specialization in this group remain uncertain, it seems clear that there is variation in its extent. Some species appear limited in their geographic range $(C$. sinica has only been found in east Asia [83]), whereas others are globally distributed [68]. Interspecific variation in seasonal predominance of wild populations has been observed, consistent with variation in fitness at different temperatures [69]. Furthermore, different Caenorhabditis species have been found associated with different bacterial communities [84], consistent with variation in bacterial preference [85]. There is also interspecific variation in the extent of dispersal carrier specificity. Some Caenorhabditis species are promiscuous in their choice of carrier; C. elegans has been found on snails, slugs, isopods, and myriapods [69]. Other species (such as C. japonica, C. angaria, and C. drosophilae), despite intensive sampling, have only been observed dispersing on one insect species in a highly host-specific manner $[68,86]$. The existence of $C$. inopinata in the fresh figs of a single species of Ficus and observations of its dispersal via pollinating wasps reveals a dramatic shift in substrate from rotting plants to fresh figs. This

\begin{tabular}{|l|l|l|l|l|l|}
\hline & & $\begin{array}{l}\text { Wasps } \\
\text { plated }\end{array}$ & $\begin{array}{l}\text { C. inopinata+ } \\
\text { after three } \\
\text { hours }\end{array}$ & $\begin{array}{l}\text { C. inopinata+ } \\
\text { after two } \\
\text { days }\end{array}$ & $\begin{array}{l}\text { C. inopinata } \\
\text { L4+ after } \\
\text { two days }\end{array}$ \\
\hline & $\begin{array}{l}\text { Pollinating } \\
\text { wasps (Plant 1) }\end{array}$ & 14 & 0 & 1 & 0 \\
\hline $\begin{array}{l}\text { Pollinating } \\
\text { wasps (Plant 2) }\end{array}$ & 15 & 8 & 10 & 4 \\
\hline $\begin{array}{l}\text { Parasitic wasps } \\
\text { (Plant 1) }\end{array}$ & 15 & 0 & 0 & 0 \\
\hline $\begin{array}{l}\text { Parasitic wasps } \\
\text { (Plant 2) }\end{array}$ & 15 & 0 & 0 & 0 \\
\hline
\end{tabular}

Fig. 5 Caenorhabditis inopinata is found traveling on pollinating fig wasps but not parasitic wasps. Left, a dispersal C. inopinata nematode has dismounted from a pollinating Ceratosolen female fig wasp that has been placed on a petri dish. The scale bar represents 10 microns. Right, a table describing wasp carrier data. Fig trees tend to fruit synchronously within a plant but asynchronously between plants [19]. In 2016, two Ficus septica plants were observed to harbor figs with actively emerging fig wasps. Emerged fig wasps were caught in a plastic bag, killed, and placed onto agar plates. Plates were subsequently monitored for dismounting C. inopinata $3 \mathrm{~h}$ and 2 days later. Here, numbers represent the number of plated wasps with disembarking C. sp. animals. C. inopinata animals were never seen dismounting from parasitic wasps despite their habitat sharing with pollinating wasps harboring C. inopinata." $L 4$, , C. inopinata animals at the fourth larval stage of development 


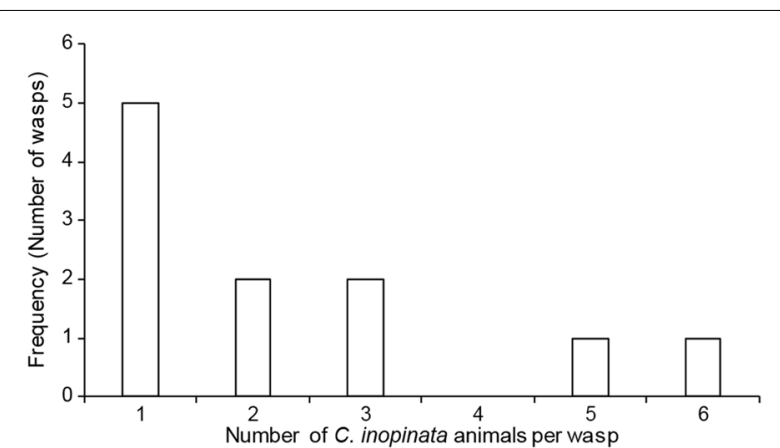

Fig. 6 Few Caenorhabditis inopinata nematodes dismount from Ceratosolen pollinating wasps. In the wasp plating experiment described in Fig. 5, the number of C. inopinata animals per wasp were also counted. This histogram reveals that of the pollinating wasps that carried C. inopinata (11/29), most carried only one to a few individuals

intimate coupling further reveals an added instance of carrier host-specificity in this group. Further, this niche shift has coincided with extreme morphological and developmental divergence [46, 47], suggesting that this change in natural history has promoted the evolution of novelties within this species. How does the move to the fig microcosm promote such change and otherwise influence their biology?

Nematodes have evolved to live in association with the fig microcosm at least nine times independently (Additional file 4: Table S9; [37, 39, 40, 87]), and in most cases, the evolution of fig-association co-occurs with dramatic changes in nutrient resource and morphology. Bursaphelenchus sycophilus is a fig parasite that evolved from fungal-feeders [37], and Parasitodiplogaster nematodes are fig wasp parasites that likely evolved from bacteriafeeders [33, 87]. Upon becoming associated with figs, the Teratodiplogaster and Parasitodiplogaster clades rapidly diverged in mouth morphology, consistent with their divergent nutrient sources (fungi and wasps, respectively) [34, 87]. In Pristionchus, the evolution of fig-association is connected with dramatic plasticity in mouth morphologies, with a single species having up to five different morphotypes [40]. And Caenorhabditis reveals rapid changes in morphology upon fig-association, with $C$. inopinata being nearly twice as long as its close relatives [46, 47]. Furthermore, in most of these fig-associated clades there are tight relationships both between nematode development and fig development [43] as well as between nematodes and fig wasps, which are utilized for dispersal or nutrient resources [33, 40, 43, 44]. The fig then represents a microcosm where functional diversification in morphology, ecology, behavior and developmental-decision making has occurred repeatedly throughout nematode phylogeny. Thus, in the case of C. inopinata, it may be unsurprising that its biology so divergent from its close relatives.

Because C. inopinata has only been observed dispersing on pollinating fig wasps (Fig. 5), it might be expected that they share similarities in population dynamics. Both pollinating wasp and C. inopinata founding populations

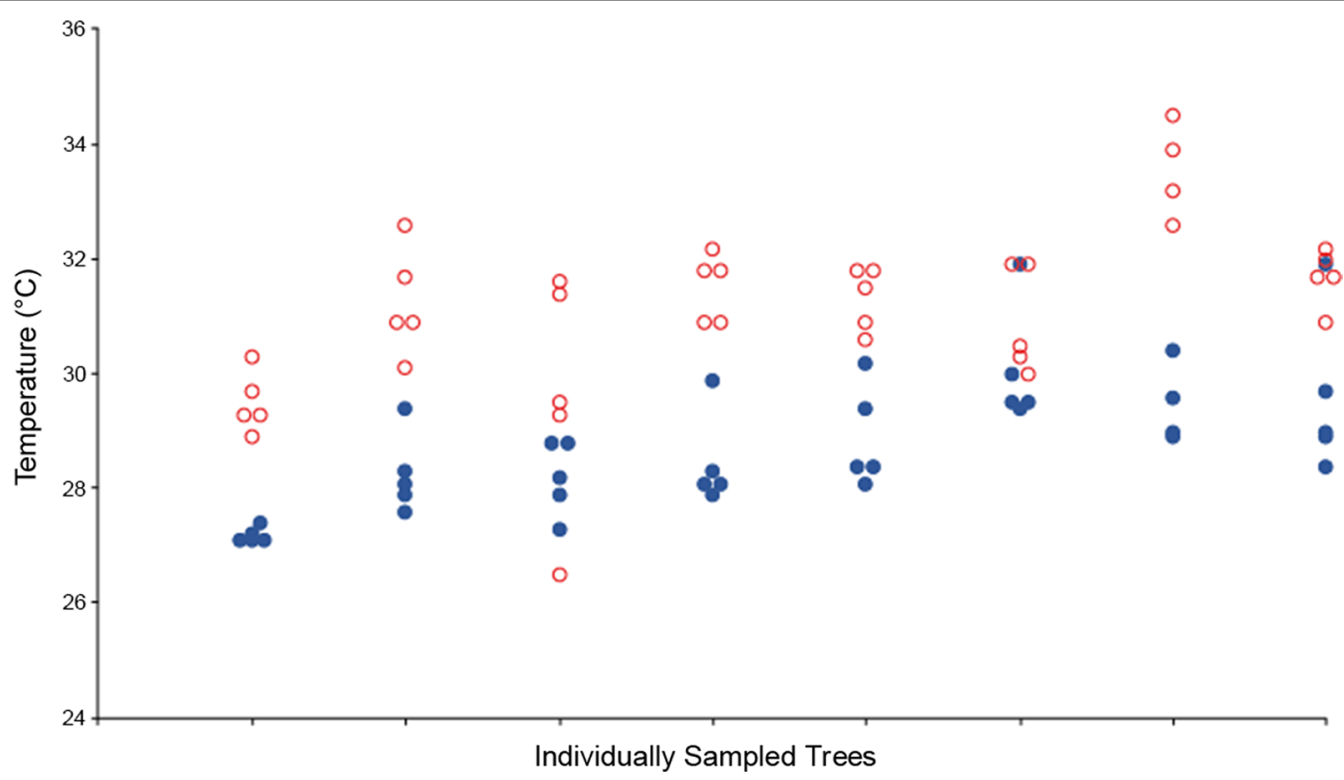

Fig. 7 Ambient and interior live F. septica fig temperatures. Live F. septica figs interiors were measured on eight plants within $1.5 \mathrm{~h}$ in the midday. Open red circles represent exterior temperatures, whereas solid blue circles denote interior fig temperatures. Fig interiors were on average $2.4^{\circ} \mathrm{C}$ cooler than exterior temperatures (t-test $p$-value $<0.001$ ) 
were observed to be quite small [a median of two foundress wasps per fig (Fig. 3) and two dispersing $C$. inopinata per wasp (Fig. 6)], consistent with previous observations of inbreeding in pollinating wasps [26, 88]. Variation in founder population size and its inbreeding effects have been shown to have consequences in local mate competition and sex ratio allocation in fig wasps [26, 27]. This may then also hold for C. inopinata, although it is possible that resource availability is different for nematodes (probably bacterial food) and wasps (fig ovules). Male/female Caenorhabditis species tend to be incredibly diverse with enormous population sizes, and C. brenneri is among the most diverse eukaryotes known [89]. The expected inbreeding in C. inopinata should reduce diversity, as has been seen in C. japonica, another Caenorhabditis male/female species with high host-specificity [90]. The selfer C. elegans displays reduced diversity, low global population structure, yet high local structure [91, 92]. This is consistent with a boom-and-bust natural history with high migration and largely clonal local populations initiated by single founders [61, 67, 68]. As C. inopinata is dispersed by wasps that can migrate over long distances while exhibiting small founder populations (Fig. 6), they may have more population genetic features in common with selfing lineages than expected of a typical gonochoristic Caenorhabditis species.

In contrast to its close relatives, C. inopinata populations are likely to be highly influenced by their fig wasp hosts. The extent of spatial population genetic structure of pollinating fig wasp species appears to vary between species. However, it is generally thought that wasps are capable of migrating long distances [93] with some species capable of dispersing over $100 \mathrm{~km}$ [94]. Consistent with this, multiple population genetic studies have revealed little spatial structure in pollinating fig wasp species [95-97], with one species (Valisia javana) revealing no isolation by distance over $1000 \mathrm{~km}$ of southeast Asia [97]. Lack of spatial structure among plant parasitic Schistonchus caprifici nematodes among Turkish [98] and southern European [99] populations are consistent with these observations. However, spatial structure is observed in some fig wasp species [100-102], and furthermore, pollination of the same fig species by different wasp species is common, with some figs being pollinated by up to four wasp species [103]. Notably, in the past decade, population genetic studies of $F$. septica and its pollinating Ceratosolen wasps themselves have been undertaken across Taiwan and the islands of southeast Asia [95, 100, 102]. Although earlier reports have noted Ceratosolen bisculatus as the only pollinator of $F$. septica in Okinawa [71], these studies have found that four species of Ceratosolen pollinate F. septica across Taiwan, the Philippines, and Okinawa $[100,102]$. These pollinators spatially overlap with analogous populations of $F$. septica, revealing a potential example of incipient local co-diversification [102]. These Ceratosolen species vary in pigmentation color (with some species black and others yellow), but only one black pollinator species was recovered in Okinawa ("Ceratosolen n. sp. 3" [102]). No yellow Ceratolosen species were observed in our figs, but additional sequencing of multiple wasps must be carried out in order to determine the extent of wasp species diversity among Okinawan F. septica figs. In any case, further molecular characterization of fig, wasp, and nematode diversity [which sequencing suggests includes at least Martininema and an undescribed rhabditid or diplogastrid in this system (Additional files 2, 3)] will be needed to fully understand the natural context of $C$. inopinata and the influence of interspecific interactions on its population dynamics.

C. inopinata also displays differences in developmental timing and developmental decision-making from their close relatives [47]. Their developmental rate is very slow compared to its close relatives [47], and dauer larvae (an alternative developmental trajectory favored under stress and dispersal conditions) are rarely seen in laboratory populations. Here, we find that reproductive stage, nondauer animals are enriched in early phase figs and dauer larvae are found in late phase figs (Fig. 4). It was not possible to absolutely confirm that these were morphological dauer larvae due to limitations in microscopy in a field setting. However, given that nearly all Caenorhabditis observed on invertebrate carriers are in the dauer stage [67], it is likely that animals found in older figs and fig wasps were indeed dauer larvae. Given that figs typically take weeks to develop [30], and that C. inopinata disperses on pollinating wasps to travel to new figs, it is reasonable to suspect that their divergence in developmental timing and decision-making are related to these features of fig biology. Although it is unclear how many generations are produced within a single fig, $C$. inopinata may have faced selective pressure to slow its developmental rate in order to match progeny production with the timing of wasp emergence. Further, given that dispersal on pollinating wasps is likely critical for C. inopinata propagation, the decision to enter into dauer may be more dependent on fig and/or wasp chemical cues than those related to stress and population density, which would explain their rarity in laboratory rearing conditions. In addition, fig-associated nematodes often disperse on fig wasps at specific stages in their development: Schistonchus fig parasites disperse at the fourth larval stage, and Parasitodiplogaster fig wasp parasites disperse at the dauer larval (or infective juvenile) stage [43]. Thus the 
modulation of developmental timing and decision-making is likely a common adaptation among fig-associated nematodes.

The impact of $C$. inopinata on fig and fig wasp fitness remains an open question. Unlike the fig parasite Schistonchus [32] and the wasp parasite Parasitodiplogaster [33], C. inopinata is unlikely to inflict direct harm on figs or wasps as a parasite. This is because $C$. inopinata maintains its typical Caenorhabditis pharyngeal morphology throughout the reproductive stages observed in fresh figs (plant parasitic nematodes typically have pharyngeal stylets [104]), and proliferative animals have not yet been associated with wasps (Figs. 4, 5). As a particle feeder, it is possible C. inopinata eats Ficus pollen, thereby affecting host fitness. This seems unlikely, however, as C. elegans cannot ingest particles greater than 4 microns in diameter [105], and Ficus pollen tends to be larger than this on average [106]. C. inopinata may affect pollinator wasp fitness through phoresy by somehow adversely affecting pollinating wasp travel across figs. Considering the size of C. inopinata dauer larvae (Fig. 1), the pervasiveness of phoresy as a dispersal strategy [107], and the contingency of worm success on wasp success in this case, a large cost to wasp dispersal ability also seems unlikely. Instead, $C$. inopinata more likely impacts host fitness indirectly through bacteriovory. Its impact may then be similar to that of Pristionchus, Acrostichus, and Teratodiplogaster, which are other microbial-feeding nematodes which have been observed in figs [36-38, 40]. Microbes harmful or beneficial for fig and wasp fitness could be a major food resource for $C$. inopinata. Ants similarly impact fig fitness by discouraging non-pollinating wasps from colonizing figs and are associated with decreased fig herbivory [76]. As measures of fig and wasp fitness (number of seeds and foundress progeny, respectively) are easily obtained [4], and contemporary metagenomic tools can define microbial communities [1], the interplay between $C$. inopinata activity, microbial communities, and host fitness should be able to be interrogated in the future. As our understanding of the Caenorhabditis-associated microbiota is rapidly increasing $[84,108,109]$, this affords an exciting opportunity for future research.

Notably, C. inopinata was found dispersing on pollinating Ceratosolen wasps, and not Philotrypesis parasitoid wasps emerging from figs of the same tree (Fig. 5). In contrast to pollinating wasps, who must enter the fig to lay eggs, Philotrypesis wasps do not enter the fig and use long ovipositors to lay eggs from the fig exterior [110]. This suggests that dispersing $C$. inopinata must discriminate within the fig to find the appropriate carrier. This would likely be a novel behavior, as its close relatives are not fig-associated and tend to be promiscuous in carrier choice [69] (although some preferences in Caenorhabditis remanei have been noted [111]). The more distantly-related $C$. japonica has been shown to have behavioral preferences for its shield bug host [112], and similar findings have been shown for Pristionchus nematodes and their host beetles [113]. In addition, it is important to note that the extent of species diversity among these Okinawan Ceratosolen wasps is still unknown, and as a consequence, it remains unclear if $C$. inopinata reveals preferences among Ceratosolen species if present. Furthermore, as nematode dispersal can occur in the wasp hemolymph [43], and since wasp dissections have not yet been performed in this system, how C. inopinata interacts with the wasp in transit remains an open question; also, our observations do not address the possibility of wasp necromeny in C. inopinata, which may occur in the fig-associated Parasitodiplogaster [33, 43]. The lack of wasp dissections (in addition to small sample sizes) among our observations here also has possibly led to underestimates of $C$. inopinata load on both pollinating and parasitic wasps (Figs. 5, 6). In any case, as mentioned above, tight associations with fig wasps is widespread among fig-associated nematodes. Nematode occupancy biases on pollinating wasps relative to parasitic wasps have been observed in the fig-associated parasitic Schistonchus and Parasitodiplogaster nematodes [43, 44], although parasitic wasps can carry nematodes [44, 114]. This typical preference for pollinating wasps has been recapitulated in a laboratory framework with Schistonchus using traditional chemotaxis assays with waspderived volatiles and cuticular hydrocarbons [45]. Similar studies could be extended to the culturable $C$. inopinata to interrogate the genetic basis of novel behaviors.

\section{Conclusion}

The elegance of contemporary molecular biology resides in the explanatory power generated by conceptual continuity across multiple hierarchical levels [115] (also known as vertical integration [116]). Such continuity is rarely found in evolutionary science-it remains unclear how the disparate pieces of population-level processes, environmental effects, developmental events, and historical contingencies interact to generate diversity in nature. Here, we described the natural history of a close relative of $C$. elegans that is associated with figs and fig wasps. The fig-fig wasp system is a legendary study system in evolution and ecology, and C. elegans is a legendary one in model systems genetics. Here then is a serendipitous convergence of research organisms that can facilitate the conceptual connection of their respective disciplines. The functional genetics of $C$. inopinata has the potential to inform the molecular basis of how ecologically-relevant phenotypes are generated, whereas the evolution and ecology of the fig system can inform 
how population-level and environmental forces sort said variation. This all begins with a simple understanding of where and how this organism lives in nature.

\section{Additional files}

\author{
Additional file 1. 2016 Ficus septica fig field data. \\ Additional file 2. Top BLAST hits for Ficus septica fig-derived COI \\ sequences.
}

Additional file 3. Alignment of Ficus septica fig-derived $\mathrm{COI}$ sequences plus additional $\mathrm{COI}$ sequences from relevant species.

Additional file 4: Supplemental Figure and Tables. Figure S1. The distribution of Ceratosolen pollinating foundress wasps among pollinated and unpollinated Ficus septica figs. Table S1. Differences in C. inopinata plant occupancy among different islands Fisher's exact test p-values. Table S2. Differences in C. inopinata fig occupancy (including pollinated figs) among different islands Fisher's exact test p-values. Table S3. Differences in C. inopinata fig occupancy (excluding pollinated figs) among different islands Fisher's exact test p-values. Table S4. C. inopinata occupancy in Ficus septica figs in 2015. Table S5. Differences in C. inopinata plant and fig occupancy in different field seasons Fisher's exact test p-values. Table S6. Differences in C. inopinata fig occupancy given different foundress number Fisher's exact test p-values. Table S7. Differences in the presence of reproductive stage $C$. inopinata given different fig stages Fisher's exact test $p$-values. Table S8. Differences in the presence of dauer stage C. inopinata given different fig stages Fisher's exact test $p$-values. Table S9. Repeated convergence of fig-association in nematodes.

\section{Authors' contributions}

GCW collected and analyzed the data. GCW and PCP wrote the paper. Both authors read and approved the final manuscript.

\section{Author details}

${ }^{1}$ Forest Pathology Laboratory, Forestry and Forest Products Research Institute, Tsukuba, Japan. ${ }^{2}$ Department of Biology, Institute of Ecology and Evolution, University of Oregon, Eugene, OR, USA.

\section{Acknowledgements}

We thank Natsumi Kanzaki for sharing his expertise in fig-associated nematode field biology.

\section{Competing interests}

The authors declare that they have no competing interests.

\section{Consent to publish}

Not applicable.

\section{Data availability}

All data used in this study are presented in the main text or Additional material.

\section{Ethics approval and consent to participate}

Not applicable.

\section{Funding}

This work was supported by funding from the National Institutes of health to GCW (5F32GM115209-03) and PCP (R01 GM-102511) and from the Japan Society for the Promotion of Science (International Research Fellowship, PE13557) to GCW.

\section{Publisher's Note}

Springer Nature remains neutral with regard to jurisdictional claims in published maps and institutional affiliations.
Received: 5 March 2018 Accepted: 30 July 2018

Published online: 21 August 2018

\section{References}

1. Nicholson JK, Holmes E, Kinross J, Burcelin R, Gibson G, Jia W, Pettersson S. Host-gut microbiota metabolic interactions. Science. 2012;336(6086):1262-7.

2. Thompson JN. The geographic mosaic of coevolution. Chicago: University of Chicago Press; 2005.

3. Anderson J, Wagner M, Rushworth C, Prasad K, Mitchell-Olds T. The evolution of quantitative traits in complex environments. Heredity. 2014;112(1):4-12.

4. Herre EA, Jandér KC, Machado CA. Evolutionary ecology of figs and their associates: recent progress and outstanding puzzles. Annu Rev Ecol Evol Syst. 2008;39:439-58.

5. Botstein D, Fink GR. Yeast: an experimental organism for 21st century biology. Genetics. 2011;189(3):695-704.

6. Bilder D, Irvine KD. Taking stock of the Drosophila research ecosystem. Genetics. 2017;206(3):1227-36.

7. Corsi AK, Wightman B, Chalfie M. A transparent window into biology: a primer on Caenorhabditis elegans. Genetics. 2015;200(2):387-407.

8. Petersen C, Dirksen P, Schulenburg H. Why we need more ecology for genetic models such as C. elegans. Trends Genet. 2015;31(3):120-7.

9. Van Belleghem SM, Rastas P, Papanicolaou A, Martin SH, Arias CF, Supple MA, Hanly JJ, Mallet J, Lewis JJ, Hines HM. Complex modular architecture around a simple toolkit of wing pattern genes. Nat Ecol Evol. 2017;1:0052.

10. Poelstra JW, Vijay N, Bossu CM, Lantz H, Ryll B, Müller I, Baglione V, Unneberg P, Wikelski M, Grabherr MG. The genomic landscape underlying phenotypic integrity in the face of gene flow in crows. Science. 2014;344(6190):1410-4.

11. Seehausen O, Terai Y, Magalhaes IS, Carleton KL, Mrosso HD, Miyagi R, van der Sluijs I, Schneider MV, Maan ME, Tachida H. Speciation through sensory drive in cichlid fish. Nature. 2008;455(7213):620.

12. Marques DA, Taylor JS, Jones FC, Di Palma F, Kingsley DM, Reimchen TE. Convergent evolution of SWS2 opsin facilitates adaptive radiation of threespine stickleback into different light environments. PLoS Biol. 2017;15(4):e2001627.

13. Lampert KP, Schmidt C, Fischer P, Volff J-N, Hoffmann C, Muck J, Lohse MJ, Ryan MJ, Schartl M. Determination of onset of sexual maturation and mating behavior by melanocortin receptor 4 polymorphisms. Curr Biol. 2010;20(19):1729-34

14. Domyan ET, Kronenberg Z, Infante CR, Vickrey Al, Stringham SA, Bruders R, Guernsey MW, Park S, Payne J, Beckstead RB. Molecular shifts in limb identity underlie development of feathered feet in two domestic avian species. Elife. 2016;5:e12115.

15. Almén MS, Lamichhaney S, Berglund J, Grant BR, Grant PR, Webster MT, Andersson L. Adaptive radiation of Darwin's finches revisited using whole genome sequencing. BioEssays. 2016;38(1):14-20.

16. Storz JF, Runck AM, Sabatino SJ, Kelly JK, Ferrand N, Moriyama H, Weber RE, Fago A. Evolutionary and functional insights into the mechanism underlying high-altitude adaptation of deer mouse hemoglobin. Proc Natl Acad Sci USA. 2009;106(34):14450-5.

17. Stinchcombe JR, Weinig C, Ungerer M, Olsen KM, Mays C, Halldorsdottir SS, Purugganan MD, Schmitt J. A latitudinal cline in flowering time in Arabidopsis thaliana modulated by the flowering time gene FRIGIDA. Proc Natl Acad Sci USA. 2004;101(13):4712-7.

18. Caicedo AL, Stinchcombe JR, Olsen KM, Schmitt J, Purugganan MD. Epistatic interaction between Arabidopsis FRI and FLC flowering time genes generates a latitudinal cline in a life history trait. Proc Natl Acad Sci USA. 2004;101(44):15670-5.

19. Bono JM, Olesnicky EC, Matzkin LM. Connecting genotypes, phenotypes and fitness: harnessing the power of CRISPR/Cas9 genome editing. Mol Ecol. 2015;24(15):3810-22.

20. Jiggins CD. The ecology and evolution of Heliconius butterflies. Oxford: Oxford University Press; 2016.

21. Heil M, McKey D. Protective ant-plant interactions as model systems in ecological and evolutionary research. Annu Rev Ecol: Evol Syst; 2003. p. 425-53. 
22. Grant PR, Grant BR. How and why species multiply: the radiation of Darwin's finches. Princeton: Princeton University Press; 2011.

23. Galil J, Eisikowitch D. On the pollination ecology of Ficus sycomorus in East Africa. Ecology. 1968;49(2):259-69.

24. Weiblen GD. How to be a fig wasp. Annu Rev Entomol. 2002;47(1):299-330

25. Moore JC, Loggenberg A, Greeff JM. Kin competition promotes dispersal in a male pollinating fig wasp. Biol Let. 2006;2(1):17-9.

26. Herre EA. Sex ratio adjustment in fig wasps. Science. 1985;228(4701):896-8.

27. West SA, Murray MG, Machado CA, Griffin AS, Herre EA. Testing Hamilton's rule with competition between relatives. Nature. 2001;409(6819):510-3.

28. Herre EA. Optimality, plasticity and selective regime in fig wasp sex ratios. Nature. 1987;329(6140):627-9

29. Jandér KC, Herre EA. Host sanctions and pollinator cheating in the fig tree-fig wasp mutualism. Proc R Soc London B Biol Sci. 2010;277(1687):1481-8

30. Janzen DH. How to be a fig. Annu Rev Ecol Syst. 1979;10(1):13-51.

31. Borges RM. How to be a fig wasp parasite on the fig-fig wasp mutualism. Curr Opin Insect Sci. 2015;8:34-40.

32. Davies KA, Ye W, Kanzaki N, Bartholomaeus F, Zeng Y, Giblin-Davis RM A review of the taxonomy, phylogeny, distribution and co-evolution of Schistonchus Cobb, 1927 with proposal of Ficophagus n. gen. and Martinineman. gen. (Nematoda: Aphelenchoididae). Nematology. 2015;17(7):761-829.

33. Poinar GO, Herre EA. Speciation and adaptive radiation in the fig wasp nematode Parasitodiplogaster (Diplogasteridae: Rhabditida) in Panama. Revue de Nématologie. 1991;14(3):361-74

34. Kanzaki N, Giblin-Davis RM, Davies K, Ye W, Center BJ, Thomas WK. Teratodiplogaster fignewmani gen. nov., sp. nov. (Nematoda: Diplogastridae) from the syconia of Ficus racemose in Australia. Zool Sci. 2009:26(8):569-78.

35. Kanzaki N, Woodruff GC, Tanaka R. Teratodiplogaster variegatae n. sp. (Nematoda: Diplogastridae) isolated from the syconia of Ficus variegata Blume on Ishigaki Island, Okinawa, Japan. Nematology. 2014;16(10):1153-66.

36. Kanzaki N, Giblin-Davis RM, Davies KA, Center BJ. Teratodiplogaster martini n. sp. and Parasitodiplogaster doliostoma n. sp. (Nematoda: Diplogastridae) from the syconia of Ficus species from Africa. Nematology. 2012;14(5):529-46.

37. Kanzaki N, Tanaka R, Giblin-Davis RM, Davies KA. New plant-parasitic nematode from the mostly mycophagous genus Bursaphelenchus discovered inside figs in Japan. PLoS ONE. 2014;9(6):e99241.

38. Davies K, Ye W, Giblin-Davis R, Thomas KW. Ficotylus congestae gen. n., sp. n. (Anguinata), from Ficus congesta (Moraceae) sycones in Australia. Nematology. 2009;11(1):63-75.

39. Giblin-Davis RM, Kanzaki N, Davies KA, Ye W, Zeng Y, Center BJ, Esquivel A, Powers TO. Ficotylus laselvae n. sp. (Tylenchomorpha: Anguinidae) associated with Ficus colubrinae in Costa Rica. Nematology. 2014;16(10):1139-51.

40. Susoy V, Herrmann M, Kanzaki N, Kruger M, Nguyen CN, Rödelsperger C Röseler W, Weiler C, Giblin-Davis RM, Ragsdale EJ. Large-scale diversification without genetic isolation in nematode symbionts of figs. Sci Adv. 2016;2(1):e1501031.

41. Abrantes IDO, dos Santos MV, da Conceição I, Santos MDA, Vovlas N. Root-knot and other plant-parasitic nematodes associated with fig trees in Portugal. Nematologia Mediterranea. 2008;36(2):131-6.

42. Esser R, Riherd C. Distribution of Aphelenchoides fragariae in leaves of Ficus elastica and Asplenium nidus. Plant Dis. 1981;65(5):425-6.

43. Giblin-Davis RM, Center BJ, Nadel H, Frank JH, Ramírez W. Nematodes associated with fig wasps, Pegoscapus spp. (Agaonidae), and syconia of native Floridian figs (Ficus spp.). J Nematol. 1995;27(1):1.

44. Vovlas N, Larizza A. Relationship of Schistonchus caprifici (Aphelenchoididae) with fig inflorescences, the fig pollinator Blastophaga psenes, and its cleptoparasite Philotrypesis caricae. Fundam Appl Nematol. 1996;19(5):443-8.

45. Krishnan A, Muralidharan S, Sharma L, Borges RM. A hitchhiker's guide to a crowded syconium: how do fig nematodes find the right ride? Funct Ecol. 2010;24(4):741-9.
46. Kanzaki N, Tsai IJ, Tanaka R, Hunt VL, Tsuyama K, Liu D, Maeda Y, Namai S, Kumagai R, Tracey A, et al. Biology and genome of a newly discovered sibling species of Caenorhabditis elegans. Nat Commun. 2018;9:3216.

47. Woodruff GC, Willis JH, Phillips PC. Dramatic evolution of body length due to post-embryonic changes in cell size in a newly discovered close relative of C. elegans. Evol Lett. 2018. https://doi.org/10.1002/evl3.67.

48. Vielle A, Callemeyn-Torre N, Gimond C, Poullet N, Gray JC, Cutter AD, Braendle $\mathrm{C}$. Convergent evolution of sperm gigantism and the developmental origins of sperm size variability in Caenorhabditis nematodes. Evolution. 2016;70(11):2485-503.

49. Kiontke KC, Félix M-A, Ailion M, Rockman MV, Braendle C, Pénigault $J$-B, Fitch DH. A phylogeny and molecular barcodes for Caenorhabditis, with numerous new species from rotting fruits. BMC Evol Biol. 2011;11(1):339.

50. Nuez I, Félix M-A. Evolution of susceptibility to ingested double-stranded RNAs in Caenorhabditis nematodes. PLoS ONE. 2012;7(1):e29811.

51. Wei Q, Zhao Y, Guo Y, Stomel J, Stires R, Ellis RE. Co-option of alternate sperm activation programs in the evolution of self-fertile nematodes. Nat Commun. 2014:5:5888.

52. Kastanakis B. Mapbox Cookbook. Birmingham: Packt Publishing Ltd; 2016.

53. Félix M-A, Braendle C, Cutter AD. A streamlined system for species diagnosis in Caenorhabditis (Nematoda: Rhabditidae) with name designations for 15 distinct biological species. PLoS ONE. 2014;9(4):e94723.

54. Hebert PD, Cywinska A, Ball SL. Biological identifications through DNA barcodes. Proc R Soc London B Biol Sci. 2003;270(1512):313-21.

55. Howe KL, Bolt BJ, Cain S, Chan J, Chen WJ, Davis P, Done J, Down T, Gao S, Grove C. WormBase 2016: expanding to enable helminth genomic research. Nucleic Acids Res. 2015. https://doi.org/10.1093/nar/gkv1217.

56. Edgar RC. MUSCLE: multiple sequence alignment with high accuracy and high throughput. Nucleic Acids Res. 2004;32(5):1792-7.

57. Barrière A, Félix M.-A. Isolation of C. elegans and related nematodes. In: WormBook, editors. The C. elegans research community, WormBook. 2014. https://doi.org/10.1895/wormbook.1.115.2, http://www.wormb ook.org.

58. Teotónio H, Estes S, Phillips PC, Baer CF. Experimental evolution with Caenorhabditis nematodes. Genetics. 2017;206(2):691-716.

59. Baugh LR. To grow or not to grow: nutritional control of development during Caenorhabditis elegans L1 arrest. Genetics. 2013;194(3):539-55.

60. Hu PJ. Dauer. In: WormBook, editors. The C. elegans research community, WormBook, 2007. https://doi.org/10.1895/wormbook.1.144.1, http:// www.wormbook.org

61. Frézal L, Félix MA. C. elegans outside the Petri dish. Elife. 2015;4:e05849.

62. Lee DL. The biology of nematodes. Boca Raton: CRC Press; 2002.

63. Dingley SD, Polyak E, Ostrovsky J, Srinivasan S, Lee I, Rosenfeld AB, Tsukikawa M, Xiao R, Selak MA, Coon JJ. Mitochondrial DNA variant in COX1 subunit significantly alters energy metabolism of geographically divergent wild isolates in Caenorhabditis elegans. J Mol Biol. 2014;426(11):2199-216.

64. Brenner S. The genetics of Caenorhabditis elegans. Genetics. 1974;77(1):71-94

65. Herre EA. Population structure and the evolution of virulence in nematode parasites of fig wasps. Science. 1993;259:1442-1442.

66. Fielenbach N, Antebi A. C. elegans dauer formation and the molecular basis of plasticity. Genes Dev. 2008;22(16):2149-65.

67. Félix M-A, Braendle C. The natural history of Caenorhabditis elegans. Curr Biol. 2010:20(22):R965-9.

68. Cutter AD. Caenorhabditis evolution in the wild. BioEssays. 2015;37(9):983-95.

69. Félix M-A, Duveau F. Population dynamics and habitat sharing of natural populations of Caenorhabditis elegans and C. briggsae. BMC Biol. 2012;10(1):1.

70. Molbo D, Machado CA, Sevenster JG, Keller L, Herre EA. Cryptic species of fig-pollinating wasps: implications for the evolution of the fig-wasp mutualism, sex allocation, and precision of adaptation. Proc Natl Acad Sci. 2003;100(10):5867-72.

71. Yokoyama J, Iwatsuki K. A faunal survey of fig-wasps (Chalcidoidea: Hymenoptera) distributed in Japan and their associations with figs (Ficus: Moraceae). Entomol Sci. 1998;1(1):37-46. 
72. Zeng Y, Ye W, Giblin-Davis RM, Li C, Zhang S, Du Z. Description of Schistonchus microcarpus n. sp. (Nematoda: Aphelenchoididae), an associate of Ficus microcarpa in China. Nematology. 2011;13(2):221-33.

73. Byerly L, Cassada R, Russell R. The life cycle of the nematode Caenorhabditis elegans: I. Wild-type growth and reproduction. Dev Biol. 1976;51(1):23-33.

74. Anderson JL, Albergotti L, Ellebracht B, Huey RB, Phillips PC. Does thermoregulatory behavior maximize reproductive fitness of natural isolates of Caenorhabditis elegans? BMC Evol Biol. 2011;11(1):157.

75. Golden JW, Riddle DL. The Caenorhabditis elegans dauer larva: developmental effects of pheromone, food, and temperature. Dev Biol. 1984;102(2):368-78.

76. Jander KC. Indirect mutualism: ants protect fig seeds and pollen dispersers from parasites. Ecol Entomol. 2015;40(5):500-10.

77. Sugiura S, Yamazaki K. Moths boring into Ficus syconia on Iriomote Island, south-western Japan. Entomol Sci. 2004;7(2):113-8.

78. Shanahan M, So S, Compton SG, Corlett R. Fig-eating by vertebrate frugivores: a global review. Biol Rev Camb Philos Soc. 2001;76(04):529-72

79. Kjellberg F, Proffit M. Tracking the elusive history of diversification in plant-herbivorous insect-parasitoid food webs: insights from figs and fig wasps. Mol Ecol. 2016;25(4):843-5.

80. Sutton TL, Riegler M, Cook JM. One step ahead: a parasitoid disperses farther and forms a wider geographic population than its fig wasp host. Mol Ecol. 2016:25(4):882-94

81. Jandér K, Dafoe A, Herre E. Fitness reduction for uncooperative fig wasps through reduced offspring size: a third component of host sanctions. Ecology. 2016. https://doi.org/10.1002/ecy.1471.

82. Sun B-F, Li Y-X, Jia L-Y, Niu L-H, Murphy RW, Zhang P, He S, Huang D-W. Regulation of transcription factors on sexual dimorphism of fig wasps. Scientific Rep. 2015:5:10696

83. Huang R-E, Ren X, Qiu Y, Zhao Z. Description of Caenorhabditis sinica sp. n. (Nematoda: Rhabditidae), a nematode species used in comparative biology for C. elegans. PLoS ONE. 2014;9(11):e110957.

84. Dirksen P, Marsh SA, Braker I, Heitland N, Wagner S, Nakad R, Mader S, Petersen C, Kowallik V, Rosenstiel P. The native microbiome of the nematode Caenorhabditis elegans: gateway to a new host-microbiome model. BMC Biol. 2016;14(1):1.

85. Glater EE, Rockman MV, Bargmann Cl. Multigenic natural variation underlies Caenorhabditis elegans olfactory preference for the bacterial pathogen Serratia marcescens. G3 Genes Genomes Genet. 2014:4(2):265-76.

86. Kiontke K. Sudhaus W. Ecology of Caenorhabditis species. In: WormBook, ed. The C. elegans research community, WormBook; 2006. https://doi. org/10.1895/wormbook.1.37.1, http://www.wormbook.org.

87. Susoy V, Ragsdale EJ, Kanzaki N, Sommer RJ. Rapid diversification associated with a macroevolutionary pulse of developmental plasticity. Elife. 2015;4:e05463.

88. Molbo D, Machado CA, Herre EA, Keller L. Inbreeding and population structure in two pairs of cryptic fig wasp species. Mol Ecol. 2004;13(6):1613-23.

89. Dey A, Chan CK, Thomas CG, Cutter AD. Molecular hyperdiversity defines populations of the nematode Caenorhabditis brenneri. Proc Natl Acad Sci USA. 2013;110(27):11056-60.

90. Li S, Jovelin R, Yoshiga T, Tanaka R, Cutter AD. Specialist versus generalist life histories and nucleotide diversity in Caenorhabditis nematodes. Proc R Soc London B Biol Sci. 2014;281(1777):20132858.

91. Barrière A, Félix M-A. High local genetic diversity and low outcrossing rate in Caenorhabditis elegans natural populations. Curr Biol. 2005:15(13):1176-84.

92. Andersen EC, Gerke JP, Shapiro JA, Crissman JR, Ghosh R, Bloom JS, Félix M-A, Kruglyak L. Chromosome-scale selective sweeps shape Caenorhabditis elegans genomic diversity. Nat Genet. 2012;44(3):285-90.

93. Nason JD, Herre EA, Hamrick JL. Paternity analysis of the breeding structure of strangler fig populations: evidence for substantial long-distance wasp dispersal. J Biogeogr. 1996:23(4):501-12.

94. Ahmed S, Compton SG, Butlin RK, Gilmartin PM. Wind-borne insects mediate directional pollen transfer between desert fig trees 160 kilometers apart. Proc Natl Acad Sci USA. 2009;106(48):20342-7.
95. Lin RC, Yeung CKL, Li SH. Drastic post-LGM expansion and lack of historical genetic structure of a subtropical fig-pollinating wasp (Ceratosolen sp. 1) of Ficus septica in Taiwan. Mol Ecol. 2008;17(23):5008-22.

96. Kobmoo N, Hossaert-Mckey M, Rasplus J, Kjellberg F. Ficus racemosa is pollinated by a single population of a single agaonid wasp species in continental South-East Asia. Mol Ecol. 2010;19(13):2700-12.

97. Tian E, Nason JD, Machado CA, Zheng L, Yu H, Kjellberg F. Lack of genetic isolation by distance, similar genetic structuring but different demographic histories in a fig-pollinating wasp mutualism. Mol Ecol. 2015;24(23):5976-91.

98. Gulcu B, Hazir S, Giblin-Davis RM, Ye W, Kanzaki N, Mergen H, Keskin $\mathrm{N}$, Thomas WK. Molecular variability of Schistonchus caprifici (Nematoda: Aphelenchoididae) from Ficus carica in Turkey. Nematology. 2008:10(5):639-49.

99. De Luca F, Castillo P, Troccoli A, Vovlas N, Landa BB, Palomares-Rius JE. Molecular variability and phylogeny of Schistonchus caprifici (Gasperrini, 1864) Cobb, 1927 (Nematoda: Aphelenchoididae) from Italy and Spain. Nematology. 2010;12(4):641-8.

100. Lin RC, Yeung CKL, Fong JJ, Tzeng HY, Li SH. The lack of pollinator specificity in a dioecious fig tree: sympatric fig-pollinating wasps of Ficus septica in Southern Taiwan. Biotropica. 2011;43(2):200-7.

101. Chen Y, Compton SG, Liu M, Chen XY. Fig trees at the northern limit of their range: the distributions of cryptic pollinators indicate multiple glacial refugia. Mol Ecol. 2012;21(7):1687-701.

102. Rodriguez LJ, Bain A, Chou L-S, Conchou L, Cruaud A, Gonzales R, Hossaert-McKey M, Rasplus J-Y, Tzeng H-Y, Kjellberg F. Diversification and spatial structuring in the mutualism between Ficus septica and its pollinating wasps in insular South East Asia. BMC Evol Biol. 2017;17(1):207.

103. Cook JM, Segar ST. Speciation in fig wasps. Ecol Entomol. 2010;35(s1):54-66.

104. Bird DM, Jones JT, Opperman CH, Kikuchi T, Danchin EG. Signatures of adaptation to plant parasitism in nematode genomes. Parasitology. 2015;142(S1):S71-84

105. Fang-Yen C, Avery L, Samuel AD. Two size-selective mechanisms specifically trap bacteria-sized food particles in Caenorhabditis elegans. Proc Natl Acad Sci USA. 2009;106(47):20093-6.

106. Wang G, Chen J, Li Z-B, Zhang F-P, Yang D-R. Has pollination mode shaped the evolution of ficus pollen? PLoS ONE. 2014:9(1):e86231.

107. Schulenburg H, Félix M-A. The natural biotic environment of Caenorhabditis elegans. Genetics. 2017;206(1):55-86.

108. Berg M, Stenuit B, Ho J, Wang A, Parke C, Knight M, Alvarez-Cohen L, Shapira M. Assembly of the Caenorhabditis elegans gut microbiota from diverse soil microbial environments. ISME J. 2016;10(8):1998-2009.

109. Samuel BS, Rowedder H, Braendle C, Félix M-A, Ruvkun G. Caenorhabditis elegans responses to bacteria from its natural habitats. Proc Natl Acad Sci USA. 2016;113(27):E3941-9.

110. Cook J, Bean D. Cryptic male dimorphism and fighting in a fig wasp. Anim Behav. 2006;71(5):1095-101.

111. Baird SE. Natural and experimental associations of Caenorhabditis remanei with Trachelipus rathkii and other terrestrial isopods. Nematology. 1999:1(5):471-5.

112. Okumura E, Tanaka R, Yoshiga T. Species-specific recognition of the carrier insect by dauer larvae of the nematode Caenorhabditis japonica. J Exp Biol. 2013;216(4):568-72.

113. Hong RL. Pristionchus pacificus olfaction. In: Sommer RJ, editor. Pristionchus pacificus: a nematode model for comparative and evolutionary biology, vol. 11. The Netherlands: Brill; 2015. p. 331-52.

114. Van Goor J, Piatscheck F, Houston DD, Nason JD. Figs, pollinators, and parasites: a longitudinal study of the effects of nematode infection on fig wasp fitness. Acta Oecol. 2018. https://doi.org/10.1016/j.actao 2018.03.007.

115. Wagner GP. The current state and the future of developmental evolution. In: Laubichler MD, Maienschein J, editors. From embryology to evo-devo: a history of developmental evolution. United States: MIT press; 2007. p. 525-45

116. Lee YW, Gould BA, Stinchcombe JR. Identifying the genes underlying quantitative traits: a rationale for the QTN programme. AoB Plants. 2014;6:plu004. 